\title{
Journal of Dermatology Research
}

Case Report

\section{Paraneoplastic Bullous Pemphigoid: Myth or Reality? A Case Report}

\author{
Sara Dahhouki ${ }^{1 *}$, S Mrabat ${ }^{1}$, Z Douhi ${ }^{1}$, S Elloudi ${ }^{1}$, H Baybay $^{1}$, FZ Mernissi ${ }^{1}$ \\ ${ }^{1}$ Dermatology Department, Hassan II Hospital University, Fez, Morocco
}

*Corresponding Author: Sara Dahhouki, Dermatology Department, Hassan II Hospital University, Fez,

Morocco; Email: dahhoukisara@gmail.com

Received Date: 05-05-2020; Accepted Date: 22-05-2020; Published Date: 29-05-2020

Copyright $^{\odot} 2020$ by Dahhouki S, et al. All rights reserved. This is an open access article distributed under the terms of the Creative Commons Attribution License, which permits unrestricted use, distribution, and reproduction in any medium, provided the original author and source are credited.

\begin{abstract}
Bullous Pemphigoid (BP) is an autoimmune sub epidermal blistering disorder. In the literature, several cases of pemphigoid associated with malignancies were reported. The association of bullous pemphigoid with cancer is still controversial. Moreover, the incidence of paraneoplastic dermatological manifestations is very low, and the incidence of paraneoplastic bullous pemphigoid is even lower. We report a 56-year-old man with paraneoplastic bullous pemphigoid which helps to discover an urothelial malignant tumor.
\end{abstract}

\section{Keywords}

Paraneoplastic Dermatological Manifestations; Urothelial Malignant tumor; Skin Biopsy

\section{Introduction}

Bullous pemphigoid is a very common autoimmune bullous dermatosis. However, paraneoplastic origin remains rare and invalid [1]. We report a patient presenting with bullous pemphigoid associated with an urothelial malignant tumor.

\section{Observation}

A 56-year-old man, a chronic smoker, presented with generalised pruritus associated with macroscopic hematuria three months earlier. One month later, the installation of bullous lesions

Dahhouki S | Volume 1; Issue 1 (2020) | JDR-1(1)-003 | Case Report

Citation: Dahhouki S, et al. Paraneoplastic Bullous Pemphigoid: Myth or Reality? A Case Report. J

Dermatol Res. 2020;1(1):1-3.

DOI: http://dx.doi.org/10.46889/JDR.2020.1103 
was noted. The dermatological examination had revealed multiple urticarial plaques and placards associated to multiple clear to hemorrhagic tense bullae. Nikolski sign was negative. The bullae were diffuse symmetrically on the trunk and limbs (Fig. 1). Mucous examination noted an erosion on the hared palate. A skin biopsy with direct immunofluorescence studies on perilesional skin was performed. Histology showed sub-epidermal cleavage with eosinophilic infiltrates. Direct immunofluorescence study showed C3 and IgG linear deposits along basement membrane confirming the diagnosis of a bullous pemphigoid. Thoraco-Abdominal CT Scanner had revealed a bladder tumor with criteria of malignancy without metastatic areas. Blood examination had objected a moderate anemia and eosinophilia. A diagnosis of paraneoplastic bullous pemphigoid was made. The patient was put on $30 \mathrm{~g}$ of very potent topical corticosteroids, clobetasol propionate, once a day, for 6 weeks and then tapered off, as a treatment of his bullous dermatosis. Some improvements in terms of reduction in the number of lesions appearing per day, and of pruritis were seen after 14 days of treatment. After resection of the tumor, most of the bullous lesions remitted.
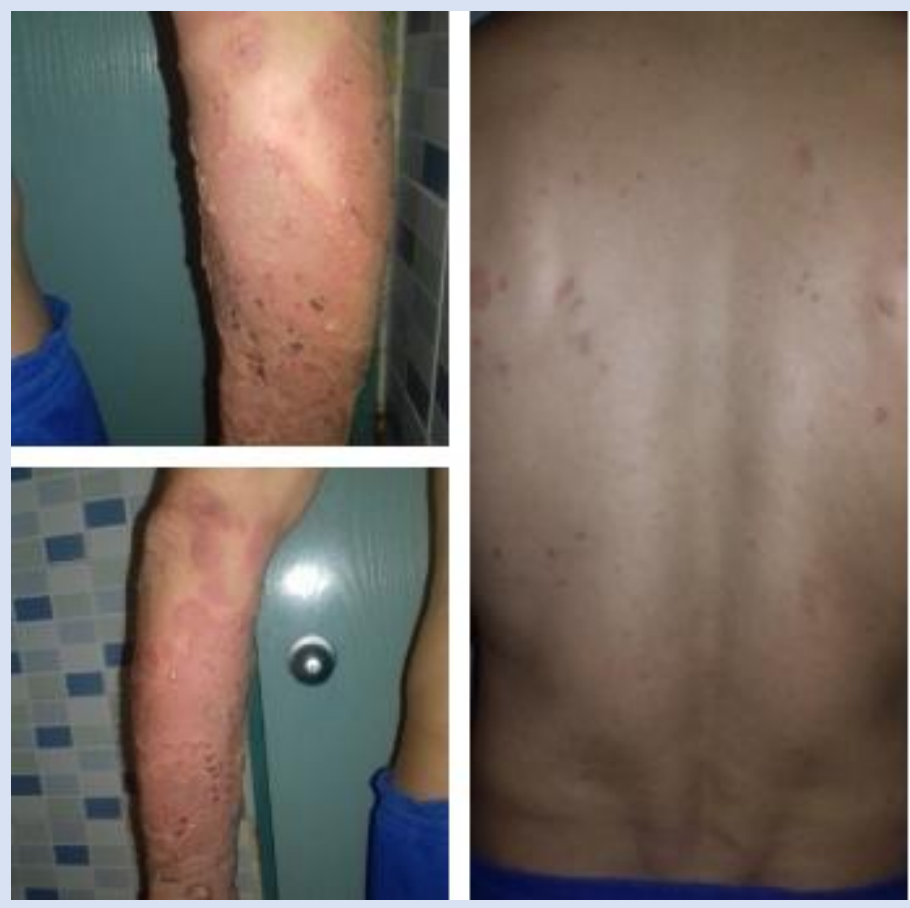
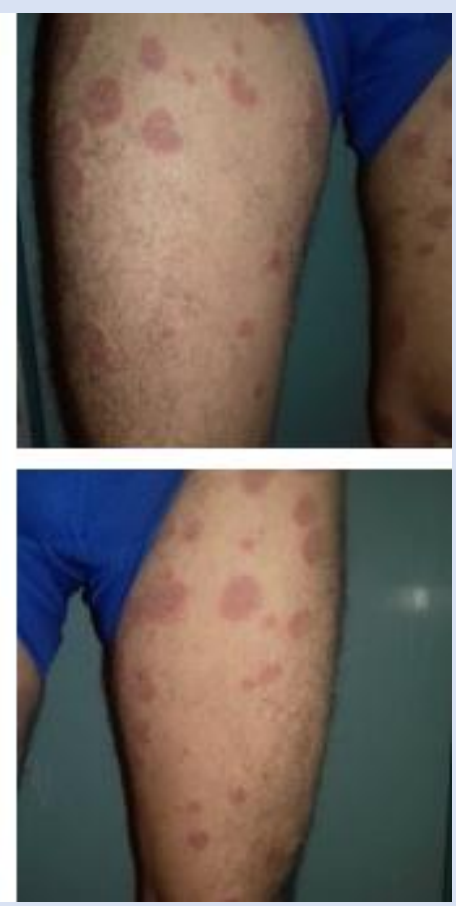

Figure1: Multiple urticarial plaques and placards associated to multiple clear to hemorrhagic tense bullae, diffuse on the trunk and limbs.

\section{Discussion}

Bullous pemphigoid is the commonest autoimmune bullous dermatosis. It forms $70 \%$ of sub epidermal autoimmune bullous dermatoses with an annual incidence of more than 400 new cases per year in the world. It affects the elderlies [2]. However, our patient was relatively young, and this is an evidence that the tumor and the bullous pemphigoid are associated. In its

Dahhouki S | Volume 1; Issue 1 (2020) | JDR-1(1)-003 | Case Report

Citation: Dahhouki S, et al. Paraneoplastic Bullous Pemphigoid: Myth or Reality? A Case Report. J 
classic form, it is clinically characterized by a bullous, pruritic dermatosis, made up of tense bullae over erythematous, symmetrical plaques, without mucosal damage or atrophic scarring, with negative Nikolsky sign. The blood examination shows frequently hyper eosinophilia, sometimes very significant [3]. Our patient had moderate eosinophilia. The diagnosis is confirmed by skin histology and direct immunofluorescence study [4]. The association of a bullous pemphigoid with cancer disease is still controversial; there are reports of improvement of bullous lesions after treatment of the tumor, which might suggest a causal relationship $[3,4]$. In our observation, the regression of dermatosis after tumor resection argues in favour of paraneoplastic characters.

\section{Conclusion}

We conclude that paraneoplastic bullous pemphigoid is a fact and not a myth. At light of this case and review of literature, it seems reasonable to us, when a bullous pemphigoid appears, especially in young people, to systematically look for an underlying cancer by a complete clinical examination and oriented para clinical examinations.

\section{Reference}

1. Lakhdar N, El Khattabi W, Lahroussi M, Afif H, Aichane A. Small cell lung cancer associated with paraneoplastic bullos pemphigoid. Rev Pneumol Clin. 2014;70(3):169-72.

2. Balestri R, Magnano M, La Placa M, Patrizi A, Angileri L, Tengattini V, et al. Malignancies in bullous pemphigoid: a controversial association. J Dermatol. 2016;43(2):125-33.

3. Jackson SR, Koestenbauer J, Carol A, Oo TH, Chou S, Indrajit B. Paraneoplastic bullous pemphigoid- A sign of clear cell renal carcinoma. Urol Case Rep. 2020;13:101119.

4. Das A, Das S, Das SK, Basuthakur S. A case of paraneoplastic bullous pemphigoid in association with squamous cell carcinoma of lung. J Postgraduate Med. 2015;61(3):197-9. 